\title{
The Four R's of Openness and ALMS Analysis: Frameworks for Open Educational Resources
}

John L. Hilton III

johnhiltoniii@byu.edu

Aaron Johnson

Jared Stein

David Wiley

david.wiley@gmail.com

Follow this and additional works at: https://scholarsarchive.byu.edu/facpub

Part of the Educational Psychology Commons

\section{Original Publication Citation}

Hilton, J., Wiley, D., Stein, J., \& Johnson, A. (21). "The four R's of openness and ALMS Analysis:

Frameworks for Open Educational Resources." Open Learning: The Journal of Open and

Distance Learning

\section{BYU ScholarsArchive Citation}

Hilton, John L. III; Johnson, Aaron; Stein, Jared; and Wiley, David, "The Four R's of Openness and ALMS Analysis: Frameworks for Open Educational Resources" (2010). Faculty Publications. 822.

https://scholarsarchive.byu.edu/facpub/822

This Peer-Reviewed Article is brought to you for free and open access by BYU ScholarsArchive. It has been accepted for inclusion in Faculty Publications by an authorized administrator of BYU ScholarsArchive. For more information, please contact ellen_amatangelo@byu.edu. 
Running head: Frameworks for OER

The Four R's of Openness and ALMS Analysis:

Frameworks for Open Educational Resources

\author{
John Hilton III, Brigham Young University ${ }^{1}$ \\ David Wiley, Brigham Young University \\ Jared Stein, Brigham Young University \\ Aaron Johnson, Brigham Young University
}

\footnotetext{
${ }^{1}$ Corresponding author. Email address is johnhiltoniii@byu.edu
} 


\begin{abstract}
A significant movement in education concerns the use of open educational resources. By "open" it is generally meant that the resource is available at no cost to others for adaptation and reuse in different contexts. However "open" is not a simple dichotomy; rather, there is a continuum of openness. We discuss four separate aspects of reuse and demonstrate how these describe different levels of openness. We discuss how the licensing and technical aspects of open educational resources affect the relative openness of an OER. Implications for those creating open educational resources are discussed.
\end{abstract}


The Four R's of Openness and ALMS Analysis:

Frameworks for Open Educational Resources

Introduction

A significant movement in education concerns the use of open educational resources (OER). Several definitions of OER have been offered. UNESCO (2002) originally defined them as "educational resources, enabled by information and communication technologies, for consultation, use and adoption by a community of users for noncommercial purposes." Bissell (2009) described OER as "digitized materials offered freely and openly for educators, students, and self-learners to use and reuse for teaching, learning and research" (97). D'Antoni (2009) cited the William and Flora Hewlett Foundation, a key donor for OER as stating that OER are "resources that reside in the public domain or have been released under an intellectual property license that permits their free use or re-purposing by others" (p. 4). An OER may be an entire course, a complete book, or a more granular piece, such as a single learning object (Downes, 2007).

An increasing number of institutions and individuals worldwide are producing and publishing OER. Amongst these, perhaps the single most well-known program is MIT's OpenCourseWare, which provides open access to materials used to teach over 1,800 courses (Atkins, Brown and Hammond, 2007). One can find a growing list of higher education institutions participating in the creation of OER by visiting the OpenCoursewareConsortium (http://www.ocwconsortium.org). As of April 2009 there were 194 members worldwide (OpenCourseWare Consortium, 2009). 
Some institutions, instead of offering full courses, offer small units of instruction such as a class module, flash video file, or lesson plan. Curriki and Rice University’s Connexions are examples of institutions providing these smaller units of educational content. Individual educators also contribute OER. Teachers have uploaded video or audio versions of lectures to YouTube or iTunes, posted PowerPoint presentations to SlideShare, and shared OER in a variety of other ways. In many instances, OER are scattered throughout various websites, but increasing efforts are being made to aggregate them (Gurrell, 2008).

The "open" in open educational resources is not a simple binary concept; rather, the construct of openness is rich and multidimensional. To use an analogy, openness is not like a light switch that is either "on" or "off." Rather it is like a dimmer switch, with varying degrees of openness. For example, the discoverability of an OER is an important aspect of how "open" it really is. In order for OER to be reused it is necessary for them to be found. If an OER cannot be discovered, from a practical perspective it might as well be closed (Brown, 2008, Dholakia, King, and Baraniuk, 2006).

Beyond discoverability, openness can be enabled or hindered in many ways. In this article we explore legal and technical measures of openness. First, we introduce the “Four R's of Openness" framework which supports finer grained thinking about the legal rights that come with OER, and therefore those OER's degree of openness. We then introduce the ALMS Analysis as a framework for thinking about the ways in which specific media types and other technology choices contribute to an OER's degree of openness. We conclude with a discussion of the implications of the frameworks for designers of open educational resources and other digital learning materials. 


\section{The Four R's of Openness}

"Open" generally means that the resource is freely available to others to reuse in different contexts (McMartin, 2007). However, the word "reuse" as it pertains to openness is poorly understood and can describe several different types of use (Downes 2007, Hylen, 2006). From a legal perspective, the critical question with regard to the different definitions of "reuse" is "do I have permission to do X with this OER?" Wiley (2009) identified four "R' $s$ " that clarify distinctions of what an OER formally permit by its license. The four R's include:

- Reuse - The most basic level of openness. People are allowed to use all or part of the work for their own purposes (e.g. download an educational video to watch at a later time).

- Redistribute-People can share the work with others (e.g. email a digital article to a colleague).

- Revise-People can adapt, modify, translate, or change the form the work (e.g. take a book written in English and turn it into a Spanish audio book).

- Remix - People can take two or more existing resources and combine them to create a new resource (e.g. take audio lectures from one course and combine them with slides from another course to create a new derivative work).

Figure 1 illustrates how allowing these different R's increases the openness of an OER. 
The baseline definition of "open" requires that the owner or copyright holder freely allows others to reuse the work. Allowing others to reuse and redistribute the work increases the openness by permitting both access and circulation. Allowing others to remix and revise the work further enhances openness, and provides opportunities for new OER to be created.

If creators of OER want their resources to be as open as possible they allow and facilitate all four R's of Openness. A key tool that creators of OER have to legally permit these four R's is open licensing. Bissell (2009) wrote that "Open licenses are critical for defining OER" (97). These licenses are necessary because many countries have laws that restrict people's ability to reuse creative works. For example, in the United States anything one creates is automatically copyrighted; therefore it is legally "closed" to reuse unless the author takes steps to open it (Lessig, 2004). The Creative Commons licenses are among the most common open licenses for OER.

Creative Commons provides several licenses to help creators of content license their work in ways consistent with their desires for openness. There are four important provisions of the Creative Commons licenses. They are: Attribution, Non-Commercial, No-Derivatives and Share-Alike. The Creative Commons website defines these terms in the following way:

Attribution. The creator allows others to copy, distribute, display, perform, and remix the copyrighted work, as long as they credit the creator. All CC licenses contain this property.

NonCommercial. The creator allows others copy, distribute, display, perform, and remix your work for non-commercial purposes only. If they 
want to use your work for commercial purposes, they must contact you for permission.

ShareAlike. The creator allows others to create remixes and derivative works based on your creative work, as long as they only distribute them under the same Creative Commons license that your original work was published under.

NoDerivatives. The creator disallows the creation of derivative works based on the original work (Creative Commons, 2009).

Thus if creators of OER want their resources to be as open as possible, they should license in the least restrictive manner (e.g. by asking for attribution only). Doing this allows other to take the resource and reuse, redistribute, revise and remix it, as long as they attribute the original author. While increased openness may be largely beneficial to the open education community, individual creators of OER may prefer that more restrictive licenses are used, depending on their goals (Gurell, 2008). Creative Commons licenses allow them to do this.

For example, if a creator of an OER did not want others reusing its resources for commercial purposes it could license the resource as "NonCommercial." If people do not want their works be revised or remixed they could use the "NoDerivatives" clause in order to allow only two of the four R's of Openness. These licensing options provide creators of OERs the ability to license their works in ways that are consistent with their desires for openness.

One challenging provision of the Creative Commons licenses is the "ShareAlike" provision (Bissell, 2009). This provision requires that individuals who revise or remix the content use the same license as carried by the original content. This is particularly problematic for those wanting to remix OER. It is for this reason that Bissell (2009) 
argues that in most cases licenses that are as unrestrictive as possible (e.g. the "Attribution only" license"), are best for both content creators and users.

One of the primary benefits of an OER is that it can be adapted, or localized, to the needs of specific situations. In order for this localization to take place, the R's of "revise" and "remix" are necessary. And for revisions and remixing to be legal a license that permits derivatives is necessary. Thus creators of OER should consider the degree to which they want their OER to be open, and license the OER accordingly. In addition to licensing there are technical aspects that make OER easier to revise and remix, and consequently affect the level of openness of an OER. The "ALMS Analysis" is a helpful framework for thinking about these technical aspects.

\section{The ALMS Analysis}

Even if a work has been licensed so that users are free to reuse, redistribute, revise and remix it, several technical factors affect openness, particularly in terms of revising and remixing. If producers of OER give people permission to use their resources, they should also consider giving them the technical keys to unlock the OERs so that they can adapt the OER to their own needs. Wiley (2009) developed the ALMS Analysis as a framework for thinking about these technical aspects of localization. ALMS is an acronym that stands for:

- Access to editing tools?

- Level of expertise required to revise or remix?

- Meaningfully editable?

- Source-file access? 
Access to editing tools. When people try to revise OER, one of the first questions they will need to ask is "What software do I use to edit this resource?" Some editing programs are available only in Windows, others only in Mac or Linux. Some editing programs are freely available (e.g. OpenOffice), while other types of files require proprietary software in order to edit them. For example although Acrobat (.pdf) files can be opened with free software, they often cannot be edited or adapted using free software. Thus access to editing tools are limited for PDF files compared to a file format like HTML

Level of expertise required to revise or remix. Some tools, such as Microsoft Word or Blogger, are easy to use and are widely used by the public in general. Other tools, such as those used to create 3D animation, are complicated to use and are only used by special communities of practice. Even if end users have access to editing tools, if they need 100 hours of training to use the tool effectively, revising OERs that rely on those tools will likely be beyond their reach. Of course there will be times when a complicated tool should be used (e.g. when a 3D animation would be more pedagogically effective). Nevertheless, creators of OER should be thoughtful about the tools they use to develop OER, and to choose the simplest tool possible.

Meaningfully editable. Perhaps the classic example of OER that are not meaningfully editable are scanned PDF documents. If a person takes handwritten notes, scans images of those notes and puts them into PDF format, the contents of the resulting file cannot be meaningfully edited. The only way to revise or remix this work is to type out the words in the PDF into a word processor document and make revisions there. In some instances a scanned PDF may be the only resource that can be provided; however, 
in many cases providers of OER could find ways to share what they are producing in such a way that the end product would be meaningfully editable by others.

Source-file access If one has not worked with extensively digital media, the notion of "source" may be foreign. A source file is the file that a programmer or developer edits and works with in order to produce a final product. In some cases the source files used by the original developer are the same files that the end-user will interact with. An example is an HTML file - the file the web developer works on is the very same file that a computer browser displays. This HTML file can be viewed by almost any web browser and copying it so that it can then be modified is relatively simple. For this reason, when you distribute an HTML file you are also providing access to the source-file because they are one and the same.

In other cases, the file the developer edits and works on is compiled into a new file for distribution, and this file cannot be edited or altered. An example of this kind of media is a Flash file. In the case of Flash, source files are named something like filename.fla, while the file a web browser reads and displays is named something like filename.swf. In order to edit a Flash file the FLA (source) file is necessary. However, because web browsers do not understand FLA files, people rarely post them online. Some may intentionally publish files that are not self-sourced, like Flash files, because they do not want other Internet users altering their work. However, for those who want others to revise and remix their work, access to the source files should be provided. 
Based on the Four R's and ALMS frameworks, we suggest the following principles for instructional designers creating materials.

Before beginning to design a piece of instruction, consider the degree to which you want the content to be open. Do you want to permit reuse and redistribution only? Do you want others to be able to remix the content? Making these decisions early in the process will clarify many other design decisions (Gibbons, 2003), including how to license the OER.

To maximize the openness of an OER, the OER should licensed in such a way that it can be reused, redistributed, revised and remixed. If your goal is to promote revision and remixing, use the least restrictive license possible (such as the Creative Commons Attribution (“BY”) license).

Open educational resources will be easy to revise or remix technically if they are meaningfully editable (like a web page), access to the source file is provided (like an HTML file), can be edited by a wide range of free or affordable software programs (like an RTF file), and can be edited with software that is easy to use and is used by many people.

Open educational resources will be difficult to revise or remix technically if they are not meaningfully editable (like scanned handwriting), are not self-sourced (like a Flash file), can only be edited by one, single platform, expensive software program (like a Microsoft OneNote file), and can only be edited with software that requires extensive training and is used by relatively few people. 


\section{Conclusion}

As the world becomes increasingly connected, open educational resources provide a significant opportunity to share both content knowledge and pedagogical practice. It is important to recognize that "openness" is not a dichotomous concept; rather, there is a continuum of openness. Designers of OER should decide early on whether they wish to facilitate reuse and redistribution only, or if they also want enable revising and remixing. Those who wish to facilitate reuse and remix of OER should license their works accordingly.

In addition, technical aspects of OER will affect how "open” they really are. Creators of OER who wish to promote revising and remixing should ensure that OER are designed in such a way that users will have access to editing tools, that the tools needed to will not require a prohibitive level of expertise, and that the OER are meaningfully editable and self-sourced. As designers of OER apply the frameworks of the "Four R's of Openness" and the "ALMS Analysis" they will be able to maximize the openness of the OER they create. 


\section{References}

Atkins, D. E., Brown, J. S., Hammond, A. L. (2007). A Review of the Open Educational Resources (OER) Movement Achievements, Challenges, and New Opportunities. Retrieved May 8, 2009, from http://learn.creativecommons.org/wpcontent/uploads/2008/03/areviewoftheopeneducationalresourcesoermovement_blo glink.pdf

Bissell, A. (2009). Permission granted: Open licensing for educational resources. Open Learning, The Journal of Open and Distance Learning, 24, 97-106.

Brown, J. S. (2008). Creating a Culture of Learning. In T. Iiyoshi \& M. S. V. Kumar, (Eds.), Opening Up Education (xi-xvii): Cambridge, MA: MIT Press.

Dholakia, U., King, J., \& Baraniuk, R. (2006). What makes an open education program sustainable? The case of Connexions. Retrieved February 26, 2009, from http://www.oecd.org/dataoecd/3/6/36781781.pdf.

Creative Commons (2009). Creative Commons Licenses. Retrieved February 27, 2009, from: http://creativecommons.org/about/licenses/meet-the-licenses.

D’Antoni, S. (2009). Open Educational Resources: Reviewing initiatives and issues. Open Learning, The Journal of Open and Distance Learning, 24, 3-10

Downes, S. (2007). Models for sustainable open educational resources. Interdisciplinary Journal of Knowledge and Learning Objects, 3, 29-44.

Gibbons, A. S. (2003). What and How Do Designers Design: A Theory of Design Structure. TechTrends, 47(5), 22-27.

Gurell, S. (2008). Open educational resources handbook for educators 1.0. Logan, UT: Center for Open and Sustainable Learning. 
Hylén, J. (2006). Open educational resources: Opportunities and challenges. From the 2006 Open Education Conference. Retrieved May 14, 2009, from: http://www.knowledgeall.com/files/Additional_Readings-Consolidated.pdf

Lessig, L. (2004). Free culture: How big media uses technology and the law to lock down culture and control creativity. New York: Penguin.

McMartin, F. (2008). Open Educational Content: Transforming Access to Education. In T. Iiyoshi \& M. S. V. Kumar, (Eds.), Opening Up Education (135-148): Cambridge, MA: MIT Press.

OpenCourseWare Consortium (2009). “Consortium members.” Retrieved May 14, 2009, from: http://www.ocwconsortium.org/members/consortium-members.html.

UNESCO. (2002). Forum on the impact of open courseware for higher education in developing countries: Final report. Retrieved May 14, 2009, from http://wcet.info/resources/publications/unescofinalreport.pdf.

Wiley (2009). Creating Open Educational Resources. Materials prepared for an independent study class on Open Educational Resources. 


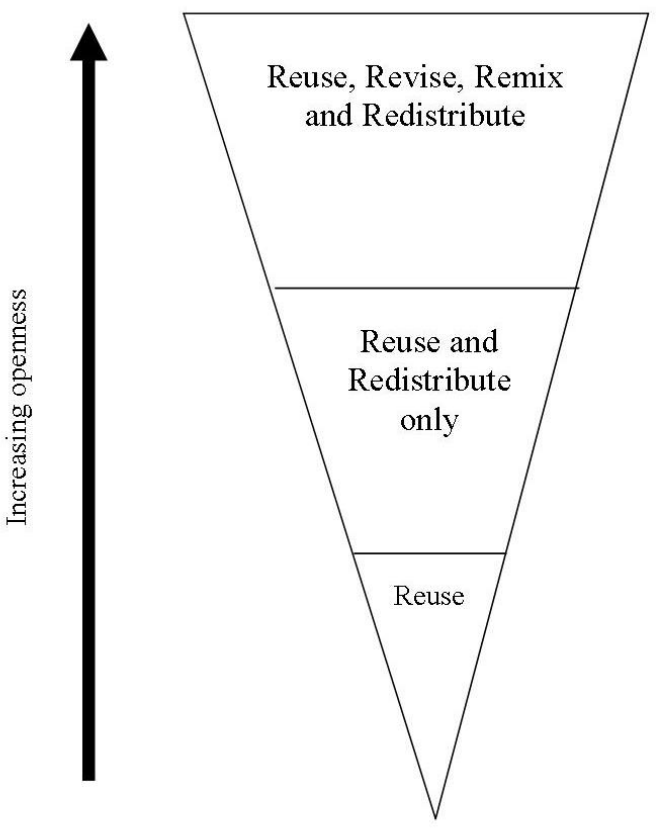

Figure 1

The Four R's and Increasing Openness

Taken from: Hilton, J. Wiley, D. (2010). "The creation and use of Open Educational Resources in Christian higher education." Christian Higher Education, Volume 9: No. 1: pp. 49-59. 